\title{
Correction to: Water sorption behavior of phenol formaldehyde resin reinforcing with reduced graphene oxide and $\mathrm{ZnO}$ decorated graphene oxide
}

\author{
P. K. Sandhya ${ }^{1} \cdot$ M. S. Sreekala ${ }^{2}$ (D) Moothetty Padmanabhan ${ }^{1,3} \cdot$ Sabu Thomas $^{1}$ \\ Published online: 21 June 2021 \\ (C) The Polymer Society, Taipei 2021
}

Correction to: Journal of Polymer Research (2021) 28:191 https://doi.org/10.1007/s10965-021-02490-5

Publisher's Note Springer Nature remains neutral with regard to jurisdictional claims in published maps and institutional affiliations.

The original version of this article unfortunately contained a mistake. The name "Sandhya P. K" should be corrected to "P.K. Sandhya".

The original article has been corrected.

The original article can be found online at https://doi.org/10.1007/ s10965-021-02490-5.

M. S. Sreekala

sreekalams@yahoo.co.in

1 School of Chemical Sciences, Mahatma Gandhi University, Kerala, Kottayam 686560, India

2 Post Graduate Research Department of Chemistry, Sree Sankara College, Kalady, Kerala 683574, India

3 Department of Chemistry, Amrita Vishwa Vidyapeetham, Kerala, Amritapuri 690525, India 